University of Nebraska - Lincoln

DigitalCommons@University of Nebraska - Lincoln

2008

\title{
TEM/QED Study of FePt Ultrathin Films and Co/CoO Core-Shell Particles
}

Xingzhong Li

University of Nebraska - Lincoln, xli2@unl.edu

T. George

University of Nebraska - Lincoln, tageorge@unlserve.unl.edu

X. H. Wei

University of Nebraska - Lincoln

David J. Sellmyer

University of Nebraska-Lincoln, dsellmyer@unl.edu

Follow this and additional works at: https://digitalcommons.unl.edu/physicssellmyer

Part of the Physics Commons

Li, Xingzhong; George, T.; Wei, X. H.; and Sellmyer, David J., "TEM/QED Study of FePt Ultrathin Films and Co/CoO Core-Shell Particles" (2008). David Sellmyer Publications. 218.

https://digitalcommons.unl.edu/physicssellmyer/218

This Article is brought to you for free and open access by the Research Papers in Physics and Astronomy at DigitalCommons@University of Nebraska - Lincoln. It has been accepted for inclusion in David Sellmyer Publications by an authorized administrator of DigitalCommons@University of Nebraska - Lincoln. 


\title{
TEM/QED Study of FePt Ultrathin Films and Co/CoO Core-Shell Particles
}

\author{
X.Z. Li, ${ }^{*}$ T. George, ${ }^{* *}$ X.H. Wei ${ }^{* *}$ and D.J. Sellmyer ${ }^{*, * *}$ \\ * Nebraska Center for Materials and Nanoscience, University of Nebraska, Lincoln, NE 68588 \\ ** Department of Physics and Astronomy, University of Nebraska, Lincoln, NE 68588
}

Transmission electron microscopy (TEM) imaging and electron diffraction (ED) techniques are widely used in the studies of thin films and nanoparticles. Although various advanced techniques have been well established, such as high-resolution electron microscopy (HREM) and convergent beam electron diffraction (CBED), the conventional TEM imaging and selected-area electron diffraction (SAED) techniques remain the essential methods for microstructure and crystal structure characterization. Digital TEM image processing and quantitative ED analysis (QED) has become one trend for improvements. Recently computer programs [1,2] have been developed for analysis of SAED patterns of polycrystalline phases. In this paper, we report the preliminary results on a TEM/QED study of FePt ultrathin films and $\mathrm{Co} / \mathrm{CoO}$ core shell particles.

The $\mathrm{L} 1_{0} \mathrm{FePt}$ alloy is an attractive candidate for use in ultrahigh density magnetic recording media. In this work, a series of FePt films of various thickness $(5.5,7.5,10,12.5 \AA)$ were prepared using magnetron sputtering on $\mathrm{Si}$ wafers with a thin layer of $\mathrm{SiO}_{2}$. Electron X-ray energy dispersive spectrum (EDS) analysis shows the composition of these films is about $\mathrm{Fe}_{58} \mathrm{Pt}_{42}$. X-ray diffraction, TEM and QED studies were carried out on both as-deposited films and those annealed at $600^{\circ} \mathrm{C}$ for $300 \mathrm{~s}$, with a focus on chemical ordering and quality of the (001) crystalline texture. The present study shows that all as-deposited films completely cover the substrate in the A1 fcc phase with grain sizes of 5-10 $\mathrm{nm}$. The annealed films are in the $\mathrm{L} 1_{0}$ fct phase and, with the exception of 12.5 $\AA$ film, show randomly distributed voids. The thinner films have a larger distribution of the voided area as seen in Fig. 1. QED studies of the annealed films reveal the chemical ordering and the (001) texture ratio based on the integrated intensities of polycrystalline diffraction rings. These results are in agreement with those found using X-ray diffraction results. Fig. 2 shows the SAED pattern of the annealed FePt film with thickness of $7.5 \AA$.

The $\mathrm{Co} / \mathrm{CoO}$ core-shell structure is attractive in the study of nano-particles for both the interest in fundamental physics and the potential application in medicine as a tracing agent for magnetic imaging. Recently an interesting proteretic loop was found in the $\mathrm{Co} / \mathrm{CoO}$ core-shell particles [3]. In the present work, nearly mono-disperse Co nano-clusters in spherical shape having sizes from 2 to $10 \mathrm{~nm}$ in diameter were produced in a cluster-beam deposition system. The core-shell clusters were then produced by partial oxidation in an oxygen atmosphere. Small clusters are found to be fully oxidized with the size about $10 \mathrm{~nm}$ whereas large clusters are the core-shell structure with the size about $20 \mathrm{~nm}$ as shown in Fig. 3. Matching of experimental and simulated SAED patterns, shown in Fig. 4, identifies that the core consists of fcc $(\mathrm{a}=3.5441 \AA)$ Co and the shell fcc $(\mathrm{a}=4.2615 \AA) \mathrm{CoO}$.

This work was supported by NSF-MRSEC, INSIC and NCMN.

\section{References}

[1] X.Z. Li, in Proceedings of Microscopy and Microanalysis (Florida, August 2007).

[2] X.Z. Li, Ultramicroscopy, 99 (2004) 257.

[3] X.-H. Wei, R. Skomski, Z.-G. Sun and D.J. Sellmyer, J. Appl. Phys. (in press). 


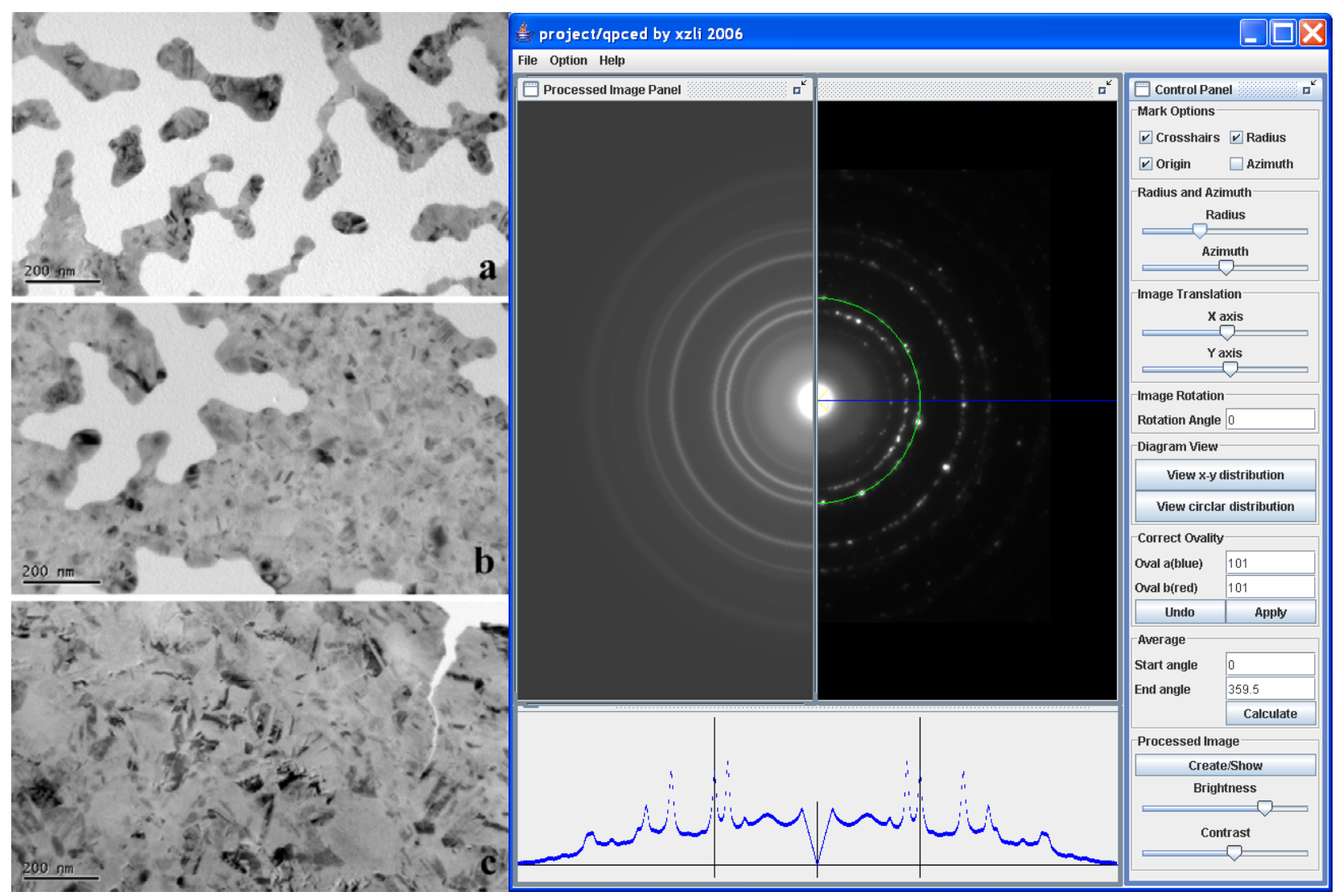

(left) Figure 1. Morphologies of the annealed FePt ultrathin films with thickness (a) $5.5 \AA$, (b) $7.5 \AA$ and (c) $12.5 \AA$. (right) Figure 2. Experimental and processed SAED patterns of the annealed FePt with thickness of $7.5 \AA$ and the profiles of the integrated diffraction intensities.

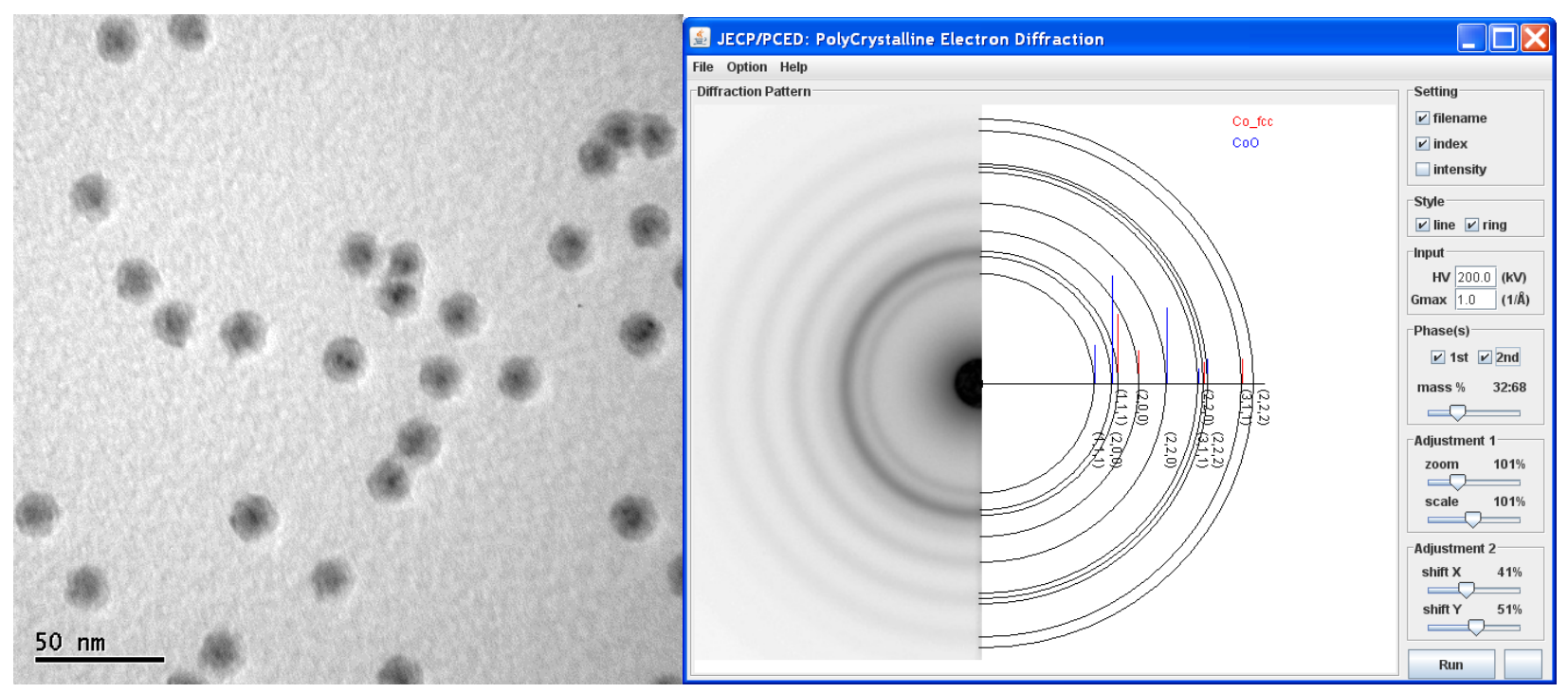

(left) Figure 3. Morphology of $\mathrm{Co} / \mathrm{CoO}$ core shell particles (20 nm in diameter), Co core in black and $\mathrm{CoO}$ shell in gray. (right) Figure 4. Experimental and calculated SAED patterns of $\mathrm{Co} / \mathrm{CoO}$ structure, identifying the $\mathrm{Co}$ core and $\mathrm{CoO}$ shell are both in fcc structure. 